\title{
CRÍTICA À MÁXIMA PARCIAL DA “NECESSIDADE” DE ROBERT ALEXY A PARTIR DA IDEIA DE “POLÍTICAS" DE RONALD DWORKIN
}

\author{
CRITICS TO PARTIAL DICTUM OF “NECESSITY” FROM ROBERT ALEXY WITH A BASIS ON THE \\ IDEA OF "POLITICS" FROM RONALD DWORKIN
}

Marcelo Antonio Theodoro ${ }^{1}$

Resumo: $\bigcirc$ artigo traz críticas à máxima parcial da "necessidade" constante na segunda etapa da "regra da proporcionalidade" desenvolvida por Robert Alexy a partir das ideias de "política" de Ronald Dworkin e, complementarmente, da "fórmula do peso" do próprio Robert Alexy. Assim, o trabalho aborda a questão da discricionariedade legislativa e da amplitude do controle judicial das leis, o que é relevante em tempos de destacado ativismo judicial. Além disso, a contraposição permite uma exposição e diferenciação das ideias de ambos os autores. Para isso, o texto, que segue o método dialético, apresenta a "regra da proporcionalidade" em suas três etapas da "adequação", "necessidade" e "proporcionalidade em sentido estrito", bem como a "fórmula do peso", por meio da qual essa última se perfaz; também apresenta os conceitos de "regras", "princípios" e "políticas" de Ronald Dworkin e, a partir disso, traça as críticas à máxima parcial da "necessidade". Os principais resultados encontrados apontam que a etapa da "necessidade" não é juridicamente exigível, mas constitui "questão de política", o que possibilita a conclusão de que o controle judicial da lei pode ser feito com base na "fórmula do peso", impedindo a edição de leis desproporcionais em sentido estrito, mas que a eleição da medida menos gravosa é uma questão política.

Palavras-chave: Discricionariedade legislativa. Revisão judicial. Fórmula do peso. Argumentos de política. Princípios jurídicos.
Abstract: The paper propose critics to the partial dictum of "necessity" present in the second step of "proportionality rule" developed by Robert Alexy with a basis in the idea of "politics" from Ronald Dworkin and, additionally, in the "weight formula" from Robert Alexy himself. In this way, the work approaches the matter of legislative discretion and extent of judicial review of laws, which is relevant in times of highlight judicial activism. Besides, the contraposition allows an exposition and differentiation of the ideas from both authors. For that, the text, which follows a dialectical method, presents the "rule of proportionality" in its three steps of "suitability", "necessity" and "proportionality in the narrower sense", as well as the "weight formula" by which this last step is done. It also presents the concepts of "rules", "principles" and "politics" from Ronald Dworkin and, from this, delineates the critics to the partial dictum of "necessity". The main results found points that the step of "necessity" is not legally chargeable, but constitutes a "matter of politic". This allows the conclusion that judicial review of law can be made by the "weight formula", preventing disproportional laws in the narrower sense to be made, but that the election of the one that interfere less with other principles is a "matter of politic".

Keywords: Legislative discretion. Judicial review. Reight formula. Arguments of politic. Legal principles.

Recebido em 26 de abril de 2018 Avaliado em 21 de junho de 2018 (AVALIADOR A) Avaliado em 08 de janeiro de 2019 (AVALIADOR B) Aceito em 10 de janeiro de 2019

\footnotetext{
1 Doutor em Direito do Estado pela Universidade Federal do Paraná; Professor na Universidade Federal de Mato Grosso, Campus Cuiabá nos Cursos de Graduação e Pós-graduação Stricto Sensu; Avenida Fernando Corrêa da Costa, 2.367, Boa Esperança, 78060-900, Cuiabá, Mato Grosso, Brasil; https://orcid.org/0000-0001-9755-0719; m.theodoro@uol.com.br

2 Bacharel em Direito pela Universidade Federal de Ouro Preto; Professor no Curso de Direito da Universidade do Estado de Mato Grosso; https://orcid.org/0000-0002-9453-362X; andre.possignolo@unemat.br
} 


\section{Introdução}

O objeto do presente artigo é a máxima parcial da "necessidade" constante na segunda etapa da "regra da proporcionalidade" desenvolvida por Robert Alexy para a solução da colisão entre princípios, especialmente de direitos fundamentais. Mais especificamente, coloca-se como problema a possibilidade de estabelecer-se uma crítica à imposição dessa etapa no controle judicial das leis, especialmente com base na ideia de "políticas" de Ronald Dworkin, mas também na própria abordagem de Robert Alexy quando trata de "fórmula do peso", considerada na terceira etapa do "método da proporcionalidade". Com isso, são abordados os limites da discricionariedade do legislador e a amplitude da revisão judicial das leis pelo judiciário.

Éimportante ressalvar que, apesar deo artigo consistir em uma crítica à etapa da "necessidade" e, portanto, da "regra da proporcionalidade" de Robert Alexy, não se pretende descaracterizá-la, de forma categórica, como método possível para a aplicação de direitos fundamentais, mas sim tecer uma crítica a uma de suas etapas que pode, sim, ser contornada. Ao revés, a "proporcionalidade" apresenta aspectos interessantes e que podem ser muito úteis na construção de uma decisão, consoante será destacado no artigo, contudo, um ponto específico de sua construção merece crítica.

Como é salientado no texto, tal crítica apresenta relevância especial em tempos nos quais o Supremo Tribunal Federal recebe desaprovações em razão de ultrapassar o texto constitucional nas fundamentações de suas decisões, um fenômeno que se denomina "ativismo judicial". Como relevância secundária, o artigo, ao contrapor ideias de Robert Alexy e Ronald Dworkin, provavelmente os dois autores mais conhecidos e aplicados da teoria do direito na atualidade, além de trazer de forma sintetizada suas teorias para aqueles que as conhecem apenas superficialmente, permite uma melhor compreensão de distinções entre eles, que muitas vezes passam despercebidas a alguns juristas.

Para cumprir o delineado nessa introdução, o artigo utiliza o método dialético, iniciando pela exposição acrítica da "regra da proporcionalidade" de Robert Alexy (seção 1) e da noção de "regras", "princípios" e "políticas" de Ronald Dworkin (seção 2) para, no final (seção 3), traçar as críticas à máxima parcial da "necessidade".

\section{A segunda etapa do "método da proporcionalidade" de Robert Alexy: a "necessidade"}

Conforme apontado na introdução, o objeto central do presente artigo é a subregra (máxima parcial) da "necessidade", constante na segunda etapa do método da "proporcionalidade" de Robert Alexy, todavia, a fim de possibilitar uma visão holística sobre a crítica, é útil contextualizar tal etapa com uma breve explicação, embora não tão simplificada quanto se costuma encontrar, do método como um todo, especialmente da "fórmula do peso", que será incorporada na crítica.

Em primeiro lugar, destaca-se a distinção entre "regras" e "princípios" na teoria de Robert Alexy. Tal distinção, segundo o autor, é importante na "teoria dos direitos fundamentais" 
- geralmente dispostos em normas caracterizadas como "princípios" -, uma vez que possibilita o alcance de soluções de problemas centrais da dogmática desses direitos, especialmente, e o que mais importa para esse artigo, a colisão e, consequentemente, a restrição de direitos fundamentais (ALEXY, 2011, p. 85-86).

Essas soluções são especialmente possíveis na concepção de Robert Alexy de que, diferente das "regras", que são ou não são satisfeitas, "princípios" são mandamentos de otimização que podem ser satisfeitos em graus diferentes e que ordenam que algo seja realizado na maior medida dentro das possibilidades fáticas e jurídicas, essas últimas, determinadas a partir das regras e princípios colidentes (ALEXY, 2011, p. 90). ${ }^{3}$ Isso significa que os princípios colidem entre si ("por exemplo, quando algo é proibido de acordo com um princípio e, de acordo com o outro, permitido"), contudo, dessa colisão não resulta a invalidade de um princípio, apenas que, em determinada situação concreta, o outro princípio tem precedência (ALEXY, 2011, p. 93-99).

Tal conceituação de "princípios como comandos de otimização conduz diretamente a uma conexão necessária entre princípios e o exame da proporcionalidade" (ALEXY, 2014, p. 5-6) (ou regra ou método da proporcionalidade, mas nunca o "princípio da proporcionalidade" (ALEXY, 2011, p. 117; ÁVILA, 1999, p. 143; SILVA, 2002, p. 24-27)). Esse exame é essencial à interpretação dos direitos - principalmente dos direitos fundamentais - de modo especial para analisar se um ato estatal destinado à realização de um direito fundamental lesa, de modo desproporcional, outro. Portanto, ela se situa como um limite ao quanto o poder público pode limitar um direito fundamental (SARLET; MARINONI; MITIDIERO, 2017, p. 409-416; SILVA, 2002, p. 24).

Essa máxima da proporcionalidade perfaz-se por três etapas ou máximas parciais na seguinte ordem pré-definida: a "adequação", a "necessidade" (mandamento do meio menos gravoso) e a "proporcionalidade em sentido estrito" (mandamento do sopesamento propriamente dito) (ALEXY, 2011, p. 116-117; SILVA, 2002, p. 30).

Sendo, os "princípios", mandamentos de otimização que exigem que algo seja realizado da melhor maneira dentro das possibilidade fáticas e jurídicas, a otimização das possibilidades fáticas refere-se às duas primeiras máximas parciais ("adequação" e "necessidade"), enquanto a otimização das possibilidades jurídicas são determinadas pela terceira máxima parcial ("proporcionalidade em sentido estrito") (ALEXY, 2014, p. 6-7).

Pela "adequação", verifica-se se determinada medida $\left(M_{1}\right)$ adotada pelo Estado é apta à persecução de um objetivo $(Z)$ que um princípio $\left(P_{\mathrm{i}}\right)$ determine a satisfação no maior grau possível. Assim, se a medida adotada $\left(M_{1}\right)$ não é adequada ao fomento do objetivo imposto pelo princípio, sua adoção é indiferente para esse princípio $\left(P_{\mathrm{i}}\right)$. Ao mesmo tempo, se essa medida afeta negativamente

\footnotetext{
3 É importante frisar que a colisão entre regras e princípios ocorre de forma diferente da colisão entre princípios: em primeiro lugar, o que se analisa é a relação entre o princípio colidente, restrito pela regra, e o princípio que sustenta a regra; em segundo lugar, nessa relação deve ser considerado, também, um princípio formal que diz que a regra deve ser obedecida. Isso é reforçado em Alexy (2014, p. 30-35).
} 
outro princípio $\left(P_{\mathrm{j}}\right)$, será vedada por esse, ao menos prima facie, sob o aspecto da otimização das possibilidades fáticas e, em decorrência do caráter deontológico desse princípio $\left(P_{\mathrm{j}}\right)$, deve ser afastada (ALEXY, 2011, p. 116-117; SILVA, 2002, p. 121).

Todavia, caso a medida adotada $\left(M_{1}\right)$ seja adequada ao fomento do primeiro princípio $\left(P_{\mathrm{i}}\right)$, mas contrária ao mandamento de otimização contido em outro princípio $\left(P_{\mathrm{j}}\right)$, deve-se passar para o exame da "necessidade".

Para essa etapa, considerar-se-á, nesse artigo, a constelação mais simples, utilizada por Robert Alexy em sua exposição. ${ }^{4}$ Pela máxima da "necessidade", deve-se verificar se a medida adotada $\left(M_{1}\right)$ pode ser substituída por uma medida alternativa $\left(M_{2}\right)$ que seja igualmente adequada para promover o objetivo $(Z)$ almejado - de forma que a adoção de uma medida $\left(M_{1}\right)$ ou outra $\left(M_{2}\right)$ seja indiferente na ótica isolada desse princípio $\left(P_{\mathrm{i}}\right)$-, porém que viole em menor grau o princípio colidente $\left(P_{\mathrm{j}}\right)$. Em outras palavras, dentre as medidas adequadas $\left(M_{1}\right.$ e $\left.M_{2}\right)$, procura-se a minimamente necessária para a satisfação do objetivo $(Z)$, no sentido de que enseje menor interferência no princípio colidente $\left(P_{\mathrm{j}}\right)$, com isso, satisfaz-se o mandamento de otimização das possibilidades fáticas imposto por esse e confirma-se seu caráter deontológico (ALEXY, 2011, p. 116-117; SILVA, 2002, p. 118-119).

Apesar de ser a "necessidade" o objeto desse trabalho, a exposição da máxima da proporcionalidade deve continuar para a finalidade pretendida.

O fato de uma medida ser "adequada" e "necessária" (no caso, adotaremos $M_{1}$ ) implica que ela é a melhor medida para promover o princípio que a fundamenta $\left(P_{\mathrm{i}}\right)$ dentro das possibilidades fáticas e que as demais medidas (como $M_{2}$ ) são proibidas de serem tomadas. Entretanto, isso não significa que essa medida $\left(M_{1}\right)$ deve ser adotada, tanto porque a análise da "necessidade" não esgota o campo das possibilidades fáticas para a realização do princípio colidente $\left(P_{\mathrm{j}}\right)$, mas apenas do princípio promovido $\left(P_{\mathrm{i}}\right)$; quanto porque, em verdade, do ponto de vista das possibilidades fáticas, o princípio lesado $\left(P_{\mathrm{j}}\right)$ é melhor realizado se nenhuma das medidas for tomada. Por isso, é essencial trazer a inter-relação entre as possibilidades fáticas e jurídicas, a partir do "sopesamento" (ALEXY, 2011, p. 116-117; SILVA, 2002, p. 119).

Com isso, chega-se à terceira etapa, a "proporcionalidade em sentido estrito", que é idêntica à "lei da ponderação": "Quanto maior o grau de não cumprimento ou de restrição de um princípio, maior deve ser a importância do cumprimento do outro". Isso é determinado pela "fórmula do peso", o que justifica o termo "sopesamento" (ALEXY, 2014, p. 6-7). Tal fórmula, em sua forma "completa e refinada" é expressa nos seguintes termos:

\footnotetext{
4 A constelação mais simples implica a análise de apenas dois princípios e dois sujeitos de direito. Entende-se que tal análise é suficiente para o presente artigo, uma vez que, como se poderá perceber na seção 3, a crítica torna-se mais contundente nas constelações mais complexas.
} 


\section{$I_{\mathrm{i}} \cdot W_{\mathrm{i}} \cdot$ \\ $W R_{\mathrm{i}}^{\mathrm{e}} \cdot R_{\mathrm{i}}^{\mathrm{n}}$ \\ $\mathrm{i}, \mathrm{j}=I_{\mathrm{j}} \cdot W_{\mathrm{j}} \cdot$ \\ $R_{\mathrm{j}}^{\mathrm{e}} \cdot R_{\mathrm{j}}^{\mathrm{n}}$}

$W_{\mathrm{i}, \mathrm{j}}$ representa o peso concreto do princípio $P_{\mathrm{i}}$ sobre o princípio $P_{\mathrm{j}}$. Como ele é estabelecido por uma divisão, podem ser concebidos três resultados: se denominador e numerador têm o mesmo valor, o quociente é 1,0 e surge o poder discricionário de optar ou não pela medida; se o numerador for maior que o numerador, o quociente é um número maior que 1,0, o que indica a prevalência do princípio $P_{\mathrm{i}}$ e a adoção da medida $M_{1}$; mas, se o denominador for maior que o numerador, hipótese em que o quociente é menor que 1,0 , determina-se a prevalência do princípio colidente $P_{\mathrm{j}}$ sobre o princípio $P_{\mathrm{i}}$ nas condições estabelecidas no caso concreto $(C)$ - mas nunca em absoluto - e a consequente proibição da medida $M_{1}$, e de qualquer outra apta a, nessas condições concretas, satisfazer o princípio $P_{\mathrm{i}}$, já que $M_{1}$ era, dentre as medidas adequadas a satisfazer $P_{\mathrm{i}}$ a mínima necessária, no sentido de que lesaria, em menor grau, $P_{\mathrm{j}}$. Então, da prevalência de um princípio sobre o outro extrai-se uma regra para aplicar-se por subsunção: "é proibido $M_{1}$ " ou "é obrigatório $M_{1}$ " (ALEXY, 2014, p. 7).

Sobre as variáveis utilizadas para chegar-se ao valor de $W_{\mathrm{i}, \mathrm{j}}$, a variável $I$ é a que permite, em maior grau, que as nuances do caso concreto sejam consideradas na equação: $I_{\mathrm{i}}$ representa a intensidade da interferência de $P_{\mathrm{i}}$ na situação em análise, enquanto $I_{\mathrm{j}}$ representa a importância do cumprimento do princípio colidente $P_{\mathrm{j}}$ ou a intensidade de interferência em $P_{\mathrm{j}}$. Por sua vez, $W_{\mathrm{i}}$ e $W_{\mathrm{j}}$ representam o peso em abstrato dos princípios $P_{\mathrm{i}}$ e $P_{\mathrm{j}}$. Todas essas variáveis $-I_{\mathrm{i}}, I_{\mathrm{j}}$, $W_{\mathrm{i}}$ e $W_{\mathrm{j}}-$ dizem respeito à "dimensão material da ponderação" e a elas são atribuídos valores em uma escala triádica: "leve" (20 ou 1), "médio" (21 ou 2) ou "grave" (24 ou 4) (ALEXY, 2014, p. 7-8 e 11-12).

Os demais fatores concernem à "dimensão epistêmica da ponderação" e só estão presentes na "fórmula do peso completa e refinada" e substituem os fatores $R_{\mathrm{i}}$ e $R_{\mathrm{j}}$, que passam a ser divididos em dois, da seguinte forma: $R_{\mathrm{i}}=R_{\mathrm{i}}^{\mathrm{e}}+R_{\mathrm{i}}^{\mathrm{n}}$ e $R_{\mathrm{j}}=R_{\mathrm{j}}^{\mathrm{e}}+R_{\mathrm{j}}^{\mathrm{n}}$, que representam a certeza das premissas empíricas $\left(R^{\mathrm{e}}\right)$ e normativas $\left(R^{\mathrm{n}}\right)$ das teses envolvendo a defesa da realização dos princípios $P_{\mathrm{i}}$ e $P_{\mathrm{j}}$ e podem, cada fator, ser substituídos por valores de uma escala triádica em que $2^{0}$ ou 1 representa "confiável" ou "certo"; $2^{-1}$ ou 1/2, "plausível"; e 2-4 ou 1/4, "não evidentemente falso" (ALEXY, 2014, p. 8-13).

Diante disso, tem-se a "segunda lei da ponderação", segundo a qual "quanto mais pesada for uma interferência em um direito fundamental, maior deve ser a certeza das premissas que a 
justificam", o que Robert Alexy, no artigo "Princípios formais" passa a entender que são tanto as premissas empíricas como as normativas (ALEXY, 2014, p. 8-13; ALEXY, 2011, p. 617).

Pela "certeza das premissas empíricas", estabelece-se o grau de certeza quanto a tese de que a intensidade da interferência de um princípio ou a importância da satisfação do princípio colidente $\left(I_{\mathrm{i}}\right.$ ou $\left.I_{\mathrm{j}}\right)$ é "grave", "média" ou "leve". Como exemplo, pode-se pensar no aborto de feto anencefálico e na tese de que esse tem possibilidade de vida extrauterina ou mesmo na certeza da tese sobre quando começa a vida humana. Desse modo, é possível fundar a decisão em uma tese apenas "plausível" ou "não evidentemente falsa", contudo será mais difícil obter um resultado favorável, tendo em vista a redução do produto causada por essa incerteza (ALEXY, 2014, p. 8-13).

De modo distinto, a "certeza das premissas normativas" só é relevante em alguns casos, e pode ser melhor compreendida diante da ideia de discricionariedade, que, segundo Robert Alexy, divide-se em dois tipos. O primeiro corresponde à "discricionariedade material", a que compreende tudo aquilo que a Constituição não proíbe nem obriga. ${ }^{5} \mathrm{O}$ segundo, à "discricionariedade epistêmica", que se subdivide em duas: a "discricionariedade epistêmica normativa" manifesta-se quando não há certeza sobre as premissas normativa, ou seja, sobre se a Constituição proíbe ou obriga o legislador a fazer algo $^{6}$; enquanto a "discricionariedade epistêmica empírica" ocorre em casos de incerteza das premissas empíricas. Nos casos de "discricionariedade epistêmica", segundo Robert Alexy, o legislador possui competência para determinar aquilo que é proibido, comandado ou deixado livre (no caso da "discricionariedade epistêmica normativa") ou, no caso de incerteza das premissas empíricas (no caso da "discricionariedade epistêmica empírica") e apenas após a realização de um procedimento de "otimização epistêmica" a partir do "modelo epistêmico", em alguns casos, o legislador pode optar por qual tese pretende seguir. ${ }^{7}$

Vale dizer, ainda, que essa discricionariedade é influenciada, em grande medida, pelos "princípio formais", especialmente o princípio que determina a prevalência prima facie da escolha política do legislador, ainda que essa nunca seja absoluta, em razão da limitação atribuída pela supremacia da Constituição e, consequentemente, dos direitos fundamentais (ALEXY, 2014, p. 13-35).

Em síntese, pode-se dizer que Robert Alexy faz uma teoria complexa de solução de colisão entre princípios, especialmente importante para a aplicação dos direitos fundamentais, que perpassa a análise a partir das máximas parciais da "adequação", da "necessidade" - que é o objeto central de crítica desse artigo -, e da "proporcionalidade em sentido estrito", que se perfaz pela análise da "fórmula do peso". Todavia, com isso, Robert Alexy não nega a existência de discricionariedade legislativa, embora a

5 Ou seja, tudo aquilo que não entra na ideia de desproporcionalidade por excesso ou por proteção insuficiente (para uma visão simplificada, mas correta, desses conceitos, ver Sarlet, Marinoni e Mitidiero (2017, p. 409-416).

6 Como exemplo, pode-se citar a existência de um mandado de criminalização do aborto, ainda que nos três primeiros meses de gestação (conforme decidiu o Tribunal Constitucional Federal da Alemanha em 25 de fevereiro de 1975). A existência de uma obrigação de criminalização nesse caso (pensando na Constituição brasileira) é "não evidentemente falsa" ou, no máximo, "plausível".

7 Alexy (2014, p. 10-13 e 22-35) (especialmente sobre a "otimização epistêmica", ver as páginas 23-30). Alexy (2011, p. 116117) e Silva (2002, p. 294). 
pretenda limitar, a partir de seu método, quando a questão envolve a restrição a direitos fundamentais. Nesse sentido é que ele reafirma a importância dos princípios formais em sua teoria.

\section{0 conceito e o momento adequado da utilização das "políticas" segundo Ronald Dworkin}

Esses conceitos da "teoria dos princípios" de Robert Alexy serão, agora, deixados em suspenso para serem retomados na seção 3, pois, no presente capítulo são trabalhadas algumas ideias da teoria de Ronald Dworkin, especialmente a de "políticas", para que ambos os autores possam, posteriormente, ser confrontados. Trata-se de uma exposição mais breve, mas suficiente em razão de ser mero instrumento à crítica que se pretende levantar.

Ronald Dworkin afirma que os juízes, especialmente nos "casos difíceis", recorrem a padrões que operam de forma diferente das "regras", como "princípios" e "políticas".

A diferença entre as "políticas" e os "princípios jurídicos" é que aquelas são um "tipo de padrão que estabelece um objetivo a ser alcançado, em geral a melhoria em algum aspecto econômico, político ou social da comunidade. ${ }^{9}$ Por outro lado, "princípios" são padrões que devem ser observados, não por promover ou assegurar uma situação econômica, política ou social considerada desejável, como as "políticas", mas por uma exigência de justiça, equidade ou alguma outra dimensão da moralidade, um exemplo trazido pelo autor que ilustra bem essa concepção é o princípio de que "os tribunais não podem ser usados como instrumento de iniquidade ou injustiça." (DWORKIN, 2010, p. 36-39).

Para diferenciá-los, Ronald Dworkin afirma que "o padrão que estabelece que acidentes automobilísticos é uma política e o padrão seguindo o qual nenhum homem deve beneficiar-se de seus próprios delitos é um princípio." (DWORKIN, 2010, p. 36-39). Nota-se, portanto, que o primeiro determina um objetivo a ser perseguido, enquanto o segundo, um comando deontológico, no caso, uma proibição.

Já a diferenciação entre "princípios" e "regras" é de natureza lógica. Embora ambos os conjuntos de padrões apontem para decisões particulares acerca da obrigação jurídica em circunstâncias específicas, a natureza da orientação que oferecem distinguem-nos (DWORKIN, 2010, p. 37-42 e 120-121).

Enquanto as "regras" são aplicáveis a "maneira do tudo-ou-nada", de forma que, configurada sua hipótese de incidência e sendo a regra válida, ela se aplica ao caso ou, do contrário, não contribui

\footnotetext{
8 Dworkin (2010, p. 36). Interessante notar que, nos capítulos 2 e 3 do livro, o autor fala, constantemente, dos juízes decidirem com base em "políticas", contudo, no capítulo 4, fala que os juízes não devem decidir com "argumentos de política", conforme será exposto nessa seção. Entende-se que, ou o autor mudou de entendimento, o que compreensível diante do fato de os capítulos terem sido publicados em momentos diferentes, ou, mais provavelmente, que nos primeiros momentos o autor está falando (1) ora de decisões em geral, não especificamente decisões judiciais, (2) ora de decisões judiciais, mas dizendo que os juízes decidem dessa forma, não que devem decidir.

9 Não se deve confundir o conceito de "políticas" em Ronald Dworkin com o de "princípios" em Robert Alexy, pois, apesar de ambos traçarem objetivos, diversas vezes a serem cumpridos pelo legislador, os objetivos traçados pelas políticas não têm caráter deontológico.
} 
para sua solução, ${ }^{10}$ e isso ocorre, principalmente, quando existe outra regra que abre uma exceção à primeira (ex.: a legítima defesa na prática de crimes); os princípios, por outro lado, enunciam "uma razão que conduz o argumento em uma certa direção, mas [ainda assim] necessita uma decisão particular", 11 a qual pode seguir ou afastar o princípio, inclusive em razão de outros princípios que argumentem em outra direção, ou mesmo de regras que lhes impõem exceção (como a usucapião em face do princípio de que ninguém deve beneficiar-se do próprio delito). Todavia, de qualquer forma, o fato de ser um princípio de direito significa que, mesmo sendo afastado, deve ser levado em conta pelas autoridades públicas no momento de decidirem. Aliás, o fato de ele ser ocasionalmente afastado é que o torna um princípio (DWORKING, 2010, p. 37-42 e 120-121).

Contudo, e isso é o que mais se repete quando se fala em Ronald Dworkin, diferentemente das regras, o fato de um princípio não ser utilizado em uma decisão em que ele deve ser considerado não remete à sua exclusão como um princípio jurídico, ou seja, à sua invalidade, isso porque os princípios apresentam uma dimensão que falta às regras, uma dimensão de peso ou importância. $\mathrm{Na}$ verdade, essa característica é da natureza dos princípios que, quando se intercruzam, devem ter sua força relativa considerada (DWORKING, 2010, p. 42-43). Nesse ponto, assim como Robert Alexy, Ronald Dworkin apresenta uma diferença qualitativa entre "regras" e "princípios".

Apesar dessa distinção, Ronald Dworkin afirma que nem sempre é possível distinguir uma regra de um princípio, tendo em vista que a forma com que são dispostos é, muitas vezes, semelhante. Dessa maneira, é necessário observar sua forma de aplicação no ordenamento jurídico para determinar se o padrão é absoluto ou não. A título de exemplo, o autor apresenta a primeira emenda à Constituição dos Estados Unidos, a qual proíbe o Congresso de cercear a liberdade de expressão: segundo alguns autores, esse padrão representa uma regra, em razão de ser um comando absoluto; outros, que enuncia um princípio que torna qualquer medida contrária à liberdade de expressão inconstitucional, salvo se seu contexto revelar a existência de outro princípio que, nas circunstâncias concretas, tenha força para gerar uma exceção (DWORKING, 2010, p. 44-45).

Sobre isso, deve-se destacar que os "princípios" não têm o condão de garantir ao juiz um poder discricionário de atribuir novas interpretações às regras. Ao revés, é necessário que se estabeleçam princípios de maior ou menor importância em um caso concreto, especialmente em um "caso difícil", e que o juiz os utilize para chegar à única resposta correta. Portanto, os "princípios" são a solução de um sistema jurídico para que a decisão de um "caso difícil" não se dê à discrição do juiz, pois esse não tem liberdade para escolher quais princípios são utilizados (DWORKING, 2010, p. 60-61).

Ademais, deve-se destacar que os "princípios", não obstante serem uma exigência da justiça, não estão além do direito, ou seja, a decisão por princípios não é uma decisão que busca argumentos

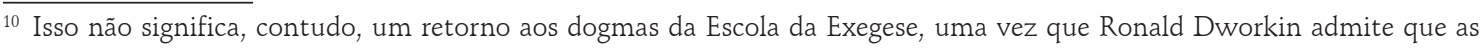
regras devem ser interpretadas para serem aplicadas e, com o decorrer do tempo, devem ser, inclusive, ampliadas e reinterpretadas (DWORKIN, 2010, p. 128-129).

$11{ }^{11}$ Colchetes no original.
} 
extralegais, ao revés, são normas jurídicas (DWORKING, 2010, p. 46-47). Essa afirmação pode ser melhor compreendida a partir da análise de Jürgen Habermas de que "há pontos de vista morais relevantes na jurisprudência, porque o direito positivo assimilou inevitavelmente conteúdos morais", ou seja, "argumentos morais entram no direito através do processo democrático da legislação." 12

Vistos esses conceitos, deve-se considerar outra questão importante: como os juízes devem decidir os "casos difíceis" ? Ou, alternativamente, como devem ser utilizados as "regras", "princípios" e "políticas" nas decisões judiciais?

Antes de adentrar nessa questão, é importante salientar que, segundo Ronald Dworkin, o direito, apesar de não ser estático, sempre traz uma resposta correta para cada caso concreto e cabe ao juiz encontrar essa resposta. Todavia, em alguns casos, os "casos difíceis", essa resposta não se encontra tão evidente e é possível que, na prática, os juízes decidam de forma divergente em questões semelhantes, mas isso não significa que não existe uma resposta correta ao caso (DWORKIN, 2010, p. 127-128).

Já sobre a aplicação desses padrões, inicialmente os juízes aplicam as regras, contudo, em razão de essas, amiúde, serem vagas, os juízes devem reinterpretá-las antes de aplicá-las a novos casos. Nessas situações, porém, eles não agem como legisladores delegados, pois não estão legislando quando, nesses "casos difíceis", vão além de decisões políticas já tomadas por outras pessoas, isso porque seus argumentos não são, ou não devem ser, "argumentos de política", mas apenas "argumentos de princípios." (DWORKIN, 2010, p. 129).

A distinção entre esses é que "[o]s argumentos de política justificam uma decisão política, mostrando que a decisão fomenta ou protege algum objetivo coletivo da comunidade como um todo", como "[o] argumento em favor de um subsídio para a indústria aeronáutica, que apregoa que tal subvenção irá proteger a defesa nacional"13; enquanto "[o]s argumentos de princípio justificam uma decisão política, mostrando que a decisão respeita ou garante um direito de um indivíduo ou

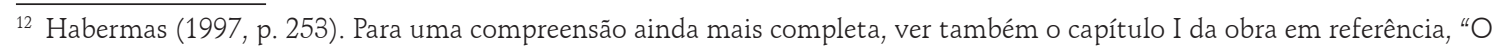
direito como categoria da mediação social entre facticidade e validade".

${ }^{13}$ Apesar de não ser esse o intuito do artigo, é oportuno o momento para tecer uma crítica ao STF no sentido de que utiliza "argumentos de política" para fundamentar determinadas decisões. Por exemplo, em alguns votos em que se justifica a não aplicação de uma lei a fim de melhorar problemas sociais demonstrados em estatísticas ou circunstâncias fáticas que se concretizam em razão da aplicação do direito, inclusive da Constituição. Um exemplo mais concreto pode ser retirado da recente Ação Penal 930, em que o relator, Ministro Roberto Barroso, decide contrário ao texto expresso da Constituição de que a prerrogativa de foro em razão da função ocorre tanto para crimes cometidos no exercício dessa, quanto para crimes comuns (esse último afastado em seu voto, já seguido pela maioria do tribunal). Em seus fundamentos, o ministro afirma, por exemplo, que "[t]amanha extensão do foro por prerrogativa de função não encontra paralelo nem na história constitucional brasileira, nem no Direito Comparado" ou que "[o] atual modelo de foro por prerrogativa de função acarreta duas consequências graves e indesejáveis para a justiça e para o Supremo Tribunal Federal. A primeira delas é a de afastar o Tribunal do seu verdadeiro papel, que é o de suprema corte, e não o de tribunal criminal de primeiro grau. Como é de conhecimento amplo, o julgamento da Ação Penal 470 (conhecida como Mensalão) ocupou o STF por 69 sessões. Tribunais superiores, como o STF, foram concebidos para serem tribunais de teses jurídicas, e não para o julgamento de fatos e provas. Como regra, o juízo de primeiro grau tem melhores condições para conduzir a instrução processual, tanto por estar mais próximo dos fatos e das provas, quanto por ser mais bem aparelhado para processar tais demandas com a devida celeridade, conduzindo ordinariamente a realização de interrogatórios, depoimentos, produção de provas periciais, etc.", dentre outros que não se apontam aqui para não desviar o foco, todos argumentos válidos do ponto de vista político, mas contrários ao que determina o direito, especificamente, nesse caso, o artigo 102, b, da Constituição da República. 
de um grupo", como "[o] argumento em favor das leis contra a discriminação, [...] segundo o qual uma minoria tem direito à igualdade de considerações e respeito." (DWORKIN, 2010, p. 129-130).

Percebe-se, portanto, que a diferença entre o "argumento de princípio" e o "argumento de política" é a finalidade perseguida e exposta no fundamento da decisão. Quando embasada em uma exigência da justiça incorporada ao direito na forma de princípios e por meio do processo legislativo (ainda que originado de uma política), em geral, fala-se de um argumento de princípio. Ao revés, quando embasada, a decisão, em objetivos coletivos da comunidade, trata-se de argumentos de política.

Ronald Dworkin ainda trata do locus de utilização desses argumentos: "[a] justificação de um programa legislativo [ou mesmo executivo] de alguma complexidade vai normalmente exigir os dois tipos de argumento." Nesse âmbito, encontram-se tanto decisões geradas por políticas e qualificadas por princípios (como subsídios a empresas, que devem respeitar o princípio da igualdade), quanto decisões geradas por princípios e qualificadas por políticas (como o combate à discriminação por meio do fomento de emprego, que pode ser restrito para não trazer consequências muito graves para a política pública, por exemplo quando se mostrarem desagregadoras) (DWORKIN, 2010, p. 130).

Quanto às decisões judiciais, aquelas "não originais", que se bastam a aplicar os termos claros de uma lei, devem ser sempre justificadas pelos argumentos de princípio, mesmo que a lei tenha sido gerada por uma política. A título de ilustração, se uma companhia aeronáutica cobra o subsídio (gerado pela política do exemplo anterior) que lhe foi negado, tanto a argumentação da companhia quanto o fundamento do juiz devem ser de princípio - ainda que esse tenha surgido de uma política -, mas não podem ser de política. No caso, não se argumenta que a defesa nacional melhora pelo fato de a empresa receber o subsídio (mesmo esse sendo o fundamento da lei), mas sim com base na lei, que já se tornou uma questão de princípio. Isso ocorre porque a lei transforma o "argumento de política" em uma "questão de princípio." (DWORKIN, 2010, p. 130-131).

A matéria fica mais complexa, todavia, quando o juiz enfrenta um "caso difícil, em que nenhuma regra estabelecida dita a decisão em qualquer direção". Para explanar essa afirmação interessa trazer o exemplo da Spartan Steel apresentado por Dworkin (2010, p. 131): a empresa demandou contra uma companhia que lhe fornecia energia elétrica cujos empregados, por negligência, romperam um cabo elétrico. Enquanto esse era consertado, a fábrica ficou fechada, razão pela qual demandou os prejuízos da companhia de energia e o tribunal teve que decidir se permitiria ou não a indenização por perda econômica decorrente de danos cometidos por negligência à propriedade alheia.

Segundo Dworkin (2010, p. 131), nesse julgamento, o tribunal poderia ter chegado a sua decisão perguntando se um empresa na posição do demandante tinha direito a uma indenização, o que é uma "questão de princípio"; mas poderia, também inquirir se seria economicamente sensato repartir a responsabilidade pelos acidentes na forma sugerida pelo demandante, o que seria uma questão de política.

Entretanto, o autor afirma que os tribunais não são legisladores segundo, portanto não podem, como faz o legislador, escolher qual desses caminhos (por políticas ou por princípios) 
seguir, mas deve decidir por princípios, já integrantes do direito. Aliás, é isso que possibilita decisões originais pelo judiciário sem lesão à democracia e sem aplicação da moralidade pessoal dos juízes. Por conseguinte, as regras aplicadas, apesar de não se encontrarem explícitas na lei, decorrem do regime dos princípios incorporados pelo direito a partir do processo legislativo. Portanto, "os juízes devem fazer novos julgamentos sobre os direitos das partes que a eles se apresentam, mas esses direitos políticos antes refletem as decisões políticas tomadas no passado do que a elas se opõe." (DWORKIN, 2010, p. 131-137).

De tudo isso, conclui-se que "[o]s argumentos de princípio são argumentos destinados a estabelecer um direito individual; os argumentos de política são argumentos destinados a estabelecer um objetivo coletivo." Então, os princípios são proposições que descrevem direitos; as políticas, que estabelecem objetivos (DWORKIN, 2010, p. 141).

Percebe-se, portanto, que, na teoria de Ronald Dworkin, os princípios são utilizados para estabelecer, em casos concretos, regras para resolver o caso individual (ainda que possam existir princípios e direitos coletivos ou abstratos), mas não para estabelecer leis gerais, o que é feito, principalmente, por argumentos de política. Isso se evidencia quando o autor afirma que "um direito é um objetivo político individuado." (DWORKIN, 2010, p. 142 e 146).

Compreendidos essas ideias, encontra-se estabelecido o arcabouço teórico necessário para tecer a crítica que se pretende trazer no presente artigo, a qual segue no capítulo seguinte.

\section{Crítica à "necessidade" de Alexy a partir da ideia de "políticas" de Dworkin}

Uma primeira consideração a se fazer ao comparar os dois autores estudados é que existe certa dificuldade decorrente do contexto de cada um - Robert Alexy situa-se no sistema alemão de civil law ou code law, enquanto Ronald Dworkin situa-se no sistema americano de commom law. Outro ponto relevante é que Robert Alexy está preocupado em estabelecer uma "teoria dos direitos fundamentais", e, dessa forma, um sistema que limite materialmente a discricionariedade do legislador, a partir da constituição, e, metodologicamente, a discricionariedade do julgador; ao revés, Dworkin está mais preocupado em contrapor-se ao sistema positivista para limitar a discricionariedade do julgador - concedida de forma ampla por esse sistema -, a partir do direito vigente estabelecido de forma explícita ou não, por regras e princípio, pelo legislador (incluso o legislador constituinte).

Sem perder de vista isso, é útil entender a diferença entre os conceitos de "política", em Ronald Dworkin, e de "princípio", em Robert Alexy. Consoante exposto, ambos evidenciam um objetivo a ser cumprido, contudo, as "políticas", para aquele, trazem objetivos da comunidade em geral, não necessariamente integrados no direito, mas que o legislador tem um dever moral ou social de seguir; enquanto "princípios", para esse, impõem objetivos jurídicos que o legislador tem um dever jurídico de seguir. 
No entanto, essa distinção não é tão simples - até porque são conceitos situados em teorias distintas -, especialmente quando se fala na máxima parcial da "necessidade".

Entendemos que o conceito de "princípio" enquanto "mandamento de otimização", pelo menos em certo sentido que será explicitado nos próximos parágrafos, é incompatível com a restrição imposta por Ronald Dworkin ao juiz quanto a decisão por políticas. ${ }^{14}$

"Em certo sentido" porque não cabe críticas quando Robert Alexy defende que princípios que expressam direitos fundamentais proíbem ou obrigam determinadas decisões legislativas, uma vez que, sendo jurídicos, deontológicos e imbuídos da primazia constitucional, são oponíveis ao legislador.

Todavia, em outro sentido, cabe a crítica quando se considera a máxima parcial da "necessidade", a qual impõe não apenas que o legislador, ao restringir determinado direito fundamental para a concretude de outro direito fundamental ou de um objetivo coletivo, o faça de maneira que a interferência nesse direito seja igual ou menor que a importância de satisfação do objetivo perseguido; mas também que essa interferência seja a mínima possível dentro das condições fáticas.

Realmente, a "necessidade" é fruto da concepção de princípios como "mandamentos de otimização" de Robert Alexy, pois, se eles mandam que algo seja cumprido na maior medida do possível, então é essencial que qualquer medida tomada seja ótima, no sentido de satisfazer um princípio lesando minimamente os demais. Contudo, isso limita extremamente qualquer poder do legislador, uma vez que exige que todas as medidas sejam ótimas, em termos de cumprir, da melhor maneira possível, os direitos fundamentais.

Com isso, não apenas se restringe demasiadamente o poder de decisão do legislador legitimamente eleito, que não só está obrigado a observar e promover os direitos fundamentais, mas de o fazer na maior medida possível. Essa otimização, entendo, não passa de um dever moral do legislador, imposto por políticas, mas não, um dever jurídico imposto por princípios de força constitucional.

Essa crítica ganha ainda mais forças quando se nota que, para perpassar a etapa da "necessidade", é imprescindível uma investigação meticulosa e transdisciplinar e que, em razão da virtual ilimitabilidade da criatividade humana, com inúmeras soluções possíveis para um único problema, de forma que é praticamente impossível esgotar os meios adequados para a persecução de um objetivo. ${ }^{15}$

É exatamente por isso, que essa investigação deve ser feita fora do âmbito jurídico e a eleição da medida para o fomento dos direitos fundamentais deve ser uma escolha política, ${ }^{16}$ de modo

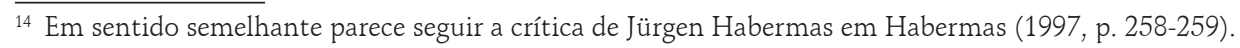

15 Para essa crítica, nem se consideram as constelações mais complexas da máxima parcial da necessidade, trabalhadas em Alexy (118, nota de rodapé 86, que tornariam necessária uma análise ainda mais aprofundada, mas apenas a constelação mais simples, que envolve uma medida do Estado apta a persecução de um objetivo frente ao direito de um indivíduo ou um grupo de indivíduos.

16 É interessante, nesse sentido, refletir sobre o fenômeno da "judicialização da política" e sua forma exacerbada, o "ativismo judicial", em que se enquadram a tomada de decisões políticas pelo judiciário. Sobre isso, ver Barroso (2012) e Vieira (2008).
} 
que o judiciário deve quedar-se, para aplicar a teoria de Robert Alexy da maneira aqui proposta, na análise da "fórmula do peso".

Ademais, parece que mesmo Robert Alexy parece reconhecer, ao menos em parte, o conteúdo dessa crítica com sua afirmação de que o legislador tem um grau de discricionariedade, mesmo em se tratando de questões relativas a direitos fundamentais, especialmente no caso da "discricionariedade epistêmica empírica", que ocorre quando não há conhecimento científico suficiente para determinar se as teses contrárias e favoráveis a uma medida são certas. Nesse caso, a incerteza epistêmica possibilita uma escolha pelo legislador entre a tese epistêmica a ser adotada, desde que essa passe pelo teste do chamado "modelo epistêmico", no qual é feita uma "ponderação de segunda ordem". ${ }^{17}$

A supressão da "necessidade" parece ainda mais evidente quando o autor refina a discricionariedade com a consideração dos "princípios formais", especialmente do princípio democrático, ${ }^{18}$ que, no modelo chamado de "modelo material-formal misto" ou "modelo da combinação", adentra a fórmula do peso no fator certeza das premissas.

Aliás, o autor delineia muito bem a problemática, e concordamos com ele nesse ponto, ao afirmar que, de um lado, conceder ampla discricionariedade ao legislador, a ponto de justificar uma interferência em direitos fundamentais, apenas em razão de ele ser democraticamente eleito, destruiria a prioridade da constituição sobre a legislação; porém, de outro, que exigir uma "precedência absoluta do princípio dos direitos fundamentais materiais sobre o princípio formal do legislador democraticamente legitimado, em várias áreas do direito" traria consequências inaceitáveis porque "conduziria a uma ampla paralisia legislativa." (ALEXY, 2014, p. 20-21 e 26).

Com último argumento, observa-se que a "necessidade" não aparece na "fórmula do peso", pois, apenas o que pode resultar dessa é que uma medida excessiva seja considerada desproporcional - logo inconstitucional caso restrinja direito fundamental -, mas não por não ser a medida que, dentro das que promovem determinado princípio, menos restringe princípios colidentes; e sim por ser uma das que não o restringe para além dos limites impostos pelos direitos fundamentais.

Assim, várias medidas, com diferentes graus de restrição ao princípio colidente, podem passar pelo teste da "fórmula do peso", embora seja verdade que aquelas que o restrinjam em menor grau tenham mais chance. Contudo, dentre essas, entendo que deve ficar a critério do legislador eleger a que deve ser aplicada.

\footnotetext{
17 Alexy (2014, p. 19-35). O caso utilizado é o da proibição penal do uso de cannabis, em que o tribunal alemão considerou plausíveis tanto a tese de que apenas com a punição penal é possível sanar um perigo elevado que existe para a saúde e para a vida social decorrente do uso do produto, quanto a tese de que o perigo elevado, presumido pelo legislador, não existe. Sobre a "ponderação de segunda ordem", ver o texto em referência.

18 Entendido no sentido de democracia representativa e, portanto, dentro da ideia de prevalência da lei. No Brasil, essa questão costuma aparecer mais em termos dos princípios formais da segurança jurídica ou da separação dos poderes, o que entendo mais válido, uma vez que "democracia" remete a uma questão mais participativa ou deliberativa. Em verdade, entendo que a eleição de representantes e o respeito a suas decisões é mais ligada à ideia de "república" que à de "democracia", portanto, nesse ponto, entendo que mesmo o princípio republicano enquadrar-se-ia melhor. Entretanto, feita essa ressalva, mantém-se com a terminologia adotada por Robert Alexy.
} 
Uma possível saída para esse problema seria incluir a questão da necessidade na terceira variável da fórmula do peso, a certeza das suposições empíricas do princípio satisfeito pela medida $\left(R_{i}^{e}\right)$. Contudo, diante da afirmação de que as medidas para concretizar um objetivo são infinitas, nunca seria possível ter certeza sobre o fato de aquela medida ser, dentre todas, a que menos afeta o princípio $P_{\mathrm{j}}$, no máximo, poder-se-ia falsear, para usar a terminologia de Popper (2008), a afirmação de que aquela medida é a menos gravosa. Dessa forma, $R_{i}^{e}$ nunca, ou com muita dificuldade, seria "confiável" ou "certo" $\left(2^{0}=1\right)$, mas, no máximo, "plausível" $\left(2^{-1}=1 / 2\right)$, o que traria uma vantagem injustificável ao princípio fomentado pela medida $\left(P_{\mathrm{i}}\right)$ e, em regra, dificultaria de forma demasiada a eleição pelo poder público, de medidas para a satisfação de objetivos constitucionalmente exigidos que colidissem com outros princípios de direitos fundamentais.

Contudo, vale notar que, ainda assim, essa solução, que aqui é rejeitada e colocada apenas a título de argumentação, torna essa adoção de medidas menos dificultosa que a etapa da "necessidade", pela qual o poder público é obrigado a escolher a medida que menos restringe o princípio colidente $\left(P_{\mathrm{j}}\right)$, ainda que existam outras que, embora mais gravosas, não sejam desproporcionais (no sentido estrito).

Conclui-se, de tudo isso que a etapa da "necessidade" busca uma mecanização quase total do processo legislativo que ultrapassa o imposto pelo direito e adentra a "questões de política".

Se por um lado é evidente que o legislador deve respeitar os mandamentos deontológicos dos direitos fundamentais a ponto de não os restringir além de certo limite, que pode ser traçado pela "fórmula do peso"; por outro, isso não conduz a um dever jurídico de escolha da medida que, dentre as que satisfazem o objetivo almejado, menos lese o direito fundamental colidente.

Afirma-se, contudo, que existe, sim, um dever de otimização imposto por "políticas" e que deve ser cobrado pelo povo, mas trata-se de um dever moral, pois a eleição de medida mais gravosa (embora proporcional em sentido estrito), não obstante configure escolha política ruim (mas que pode embasar-se em outros fatores políticos, mesmo a aceitabilidade social), configura-se em uma escolha política válida.

\section{Conclusão}

O que se sugere com a crítica exposta no artigo não é uma ampla discricionariedade do legislador, a ponto de poder intervir de maneira irrestrita ou arbitrária nos direitos fundamentais apenas por ser legitimamente competente para a edição de leis. Ao revés, defende-se apenas uma discricionariedade mais ampla que a sugerida por Robert Alexy no sentido de que a lei, embora deva passar por uma análise de constitucionalidade, não precisa eleger a medida que menos restrinja um direito fundamental colidente, mas apenas aquela que se justifique em razão de a importância de satisfação do direito fundamental promovido ser igual ou maior que o nível de interferência ao direito fundamental restringido. Aliás, também não rejeita a teoria de Robert Alexy, que pode ser empregada com as modificações sugeridas. 
Ao revés, o que se defende é que a análise da "necessidade" não é apenas desnecessária (ou até insuperável), mas também não é quista como limite a legislador, uma vez que o restringe demasiadamente.

O problema que surge com a exigência da "necessidade", como pode ser visto, decorre da diferença entre: exigir uma otimização no sentido de que a medida a ser tomada para fomentar um direito fundamental seja suficiente para compensar a interferência em outro direito fundamental; e exigir que não apenas essa importância seja suficiente para justificar a interferência, mas que a interferência seja a menor possível. Dessa diferença, pode-se perceber que mesmo uma medida que não passe pela "necessidade" pode passar pelo "sopesamento", e é esse que se defende como uma imposição jurídica possível, e judicialmente controlável, ao legislador.

Aliás, repito, ao falar de discricionariedade e da relevância do princípio formal da democracia, ou mesmo da segurança jurídica, Robert Alexy parece reconhecer que mesmo uma medida que não passe pela etapa da "necessidade", ela pode ser juridicamente aceita.

É válido afirmar, contudo, que, obviamente, o legislador deve procurar otimizar a realização dos direitos fundamentais e, por isso, deve buscar medidas que efetivem direitos fundamentais de forma a limitar minimamente os direitos colidentes, contudo, esse deve não é imposto por "princípios", mas por "políticas", no sentido dworkiniano. Nesse sentido, configura-se um dever moral do legislador de buscar essa eficiência, mas isso não deve ser imposto pelo judiciário (mas sim pelo povo) ao legislador, sob pena de afetar o núcleo essencial da separação dos poderes e promover o já tão presente ativismo judicial. Em outras palavras, o lócus de utilização da máxima parcial da necessidade de Robert Alexy é o político, não o jurídico.

Em suma, é preciso, principalmente em tempos de ativismo judicial crescente e ausência de controles de tribunais superiores como ocorre atualmente no Brasil, saber diferenciar, no momento de fazer a crítica ao legislativo, quais críticas se baseiam em "questões de princípio", portanto em questões jurídicas, e quais se baseiam em "questões de política", portanto em questões morais.

\section{Referências}

ALEXY, Robert. Princípios formais. In: TRIVISONNO, Alexandre Travessoni Gomes; SALIBA, Aziz Tuffi; LOPES, Mônica Sette (org.). Princípios formais e outros aspectos da teoria discursiva do direito. 1. ed. Rio de Janeiro: Forense Universitária, 2014.

ALEXY, Robert. Teoria dos direitos fundamentais. Tradução: Virgílio Afonso da Silva. 2. ed. São Paulo: Malheiros, 2011.

ÁVILA, Humberto Bergmann. A distinção entre princípios e regras e a redefinição do dever de proporcionalidade. Revista de Direito Administrativo, Rio de Janeiro, v. 215, p. 151-179, jan./mar. 1999

BARROSO, Luís Roberto. Judicialização, ativismo judicial e legitimidade democrática. [Syn]Thesis, Rio de Janeiro, v. 5, n. 1, p. 23-32, 2012. 
DWORKIN, Ronald. Levando os direitos a sério. Tradução: Nelson Boeira. 3. ed. São Paulo: WMF Martins Fontes, 2010.

HABERMAS, Jürgen. Direito e democracia: entre facticidade e validade. Tradução: Flávio Beno Siebeneichler. Rio de Janeiro: Tempo Brasileiro, 1997. v. 1.

POPPER, Karl Raimund. A lógica da pesquisa científica. Tradução: Leonidas Hegenberg e Octanny Silveira da Mota. 16. ed. São Paulo: Cultrix, 2008.

SARLET, Ingo Wolfgang; MARINONI, Luiz Guilherme; MITIDIERO, Daniel. Curso de direito constitucional. 6. ed. São Paulo: Saraiva, 2017.

SILVA, Virgílio Afonso da. O proporcional e o razoável. Revista dos Tribunais, a. 91, v. 798, p. 23-50, abr. 2002 .

VIEIRA, Oscar Vilhena. Supremocracia. Revista Direito GV, São Paulo, v. 2, n. 4, p. 441-464, jul./ dez. 2008. 